\title{
DE BESTIAS, ARISTÓCRATAS Y FANTASMAS: SERES NO HUMANOS $Y$ PATRIMONIO EN UNA ESTANCIA ENCANTADA DE LA PAMPA BONAERENSE
}

- YANINAFACCIO 1

1 Profesora y licenciada en Letras por la Universidad de Buenos Aires, diplomada en Antropología Social y Política por FLACSO y actual becaria doctoral del Consejo Nacional de Investigaciones Científicas y Técnicas de Argentina, con lugar de trabajo en el Instituto de Altos Estudios Sociales de la Universidad Nacional de San Martín. E-mail de contacto: yfaccio@gmail.com

Recebido em: 14/06/2020

Aprovado em: 20/08/2020



Resumen: Este artícula aborda un fenómeno que, desde que comencé a hacer trabajo etnográfico en un partido del naraeste de la provincia de Buenos Aires, mis interlacutares no han dejada de "traer": el de la presencia de una niña fantasma en las edificaciones que rodean a una estancia en ruinas, en una zona actualmente dominada por la producción agroindustrial. La última aparición pública de este joven espectro femenina ocurrió en una capilla neogótica abandanada y generó - difusión mediática mediante - un intenso tráfica de visitantes atraídos por la idea de tener un encuentro con ella. Esta situación desembocó en no pocas rispideces con los propietarios, que, desterritarializados, residen en ciudades de mayor envergadura. Aquí, me propongo seguir la histaria de esta aparición en dos aspectos. Por un lada, reconstruiré las versiones acerca de los orígenes de la niña fantasma, signadas por la violencia. Por otra, me centraré en los encuentras que mis interlacutares han tenida can ella, en la difusión de su existencia - que se amplificó del "baca en boca" lacal a instancias mediáticas mayores y en las consecuencias que ello trajo. Esto me llevará a reflexionar sobre los procesos de patrimanialización y turistificación así como sabre el peso que las "experiencias extraordinarias" pueden tener para desencadenarlos, en una zona en la que la soja avanza, con pasa firme, sobre infraestructuras que alguna vez dieron cobijo a vidas humanas y que hoy se encuentran, aparentemente, desactivadas.

Palabras clave: fantasmas, patrimania, turismo, despablamienta, lugares de mieda. 
BEASTS, ARISTRDCRATS AND PHANTDMS: NUN-HUMANS AND HERITAGE IN AN ENCHANTED FARM IN THE PAMPA BONAERENSE

ABSTRACT: THIS PAPER ADDRESSES A PHENDMENDN THAT HAS CDME UP PERSISTENTLY DURING MY FIELDWDRK IN AN INNER RURAL CDUNTY IN BUENDS AIRES PROVINCE; THAT IS: THE STORIES ABDUT A GHOST GIRL WHO HAUNTS AN OLD FARM IN RUINS, IN AN AREA CURRENTLY DUMINATED BY AGRD-INDUSTRIAL PRDDULCTION. THE LAST PUBLIC APPEARANCE OF THIS YOUNG FEMALE PHANTDM OCELURRED IN AN ABANDONED NEQ-GDTHIC CHAPEL AND CREATED AN INTENSE TRAFFIC OF VISITDRS, ATTRACTED BY THE IDEA DF HAVING A CLOSE ENCDUNTER WITH HER. THIS SITUATION LED TO VARIDUS CONFLICTS WITH THE FIELD OWNERS, WHO CURREETLY LIVE IN BUENDS AIRES CITY. HERE, I FOLLOW THE STORY OF THIS YOUNG FEMALE GHOST, FOCUSING ON TWD ASPECTS. ON QNE HAND, I RECDNSTRUCT THE VERSIONS ABDUT HER ORIGINS, MARKED BY VIOLENCE. ON THE OTHER, I FOCUS GN THE ENCDUNTERS MY INTERLOCUTORS HAVE HAD WITH HER, QN THE DISSEMINATIIN OF THE RLMUULRS ABDUT HER EXISTENCE, AND ON THEIR CONSEDUENCES. THIS WILL LEAD ME TO REFLECT ON ISSUES SUCH AS HERITAGE, TOURISM AND "EXTRADRDINARY EXPERIENCES" IN AN AREA WHERE SDY IS CURRENTLY DISMANTLING INFRASTRUCTURES THAT USED TO HOLD SOCIAL TISSUES AND HUMAN LIVES.

KEYWDRDS: GHDSTS, HERITAGE, TOURISM, DEPOPULATION, SPACES DF FEAR.

\section{DE BESTIAS, ARISTUCRATAS E FANTASMAS: SERES NÃ̃ HUMANDS E PATRIMÎNII NUMA ESTÂNCIA ENCANTADA DA PAMPA BONAERENSE}

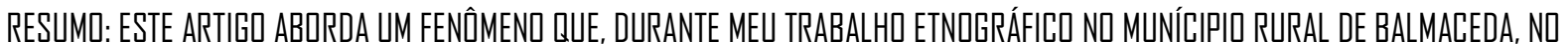
INTERIDR DA PRDVÍNCIA DE BUENDS AIRES, MEUS INTERLDCUTDRES NÃ̃ TÊM DEIXADO DE "TRAZER" PARA MIM: — DA EXISTÊNCIA DE UMA PEDUENA MENINA FANTASMA NAS EDIFICAC̄̃̃ES QUE CIRCLNNDAM UMA FAZENDA EM RUÍNAS, LOCALLZADA NUMA REEIÃ̃ DUMINADA

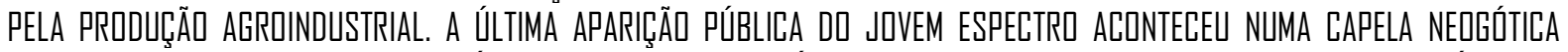
ABANDONADA E GERDU UM INTENSD TRÁFEG DE VISITANTES ATRAÍDOS PELA IDEIA DE TER UM ENCDNTRD CDM I MAIS-ALÉM. ESSA

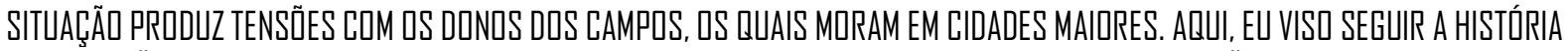
DA APARIÇÃ̃ LEVANDO EM CONTA DOIS ASPECTDS. POR UM LADD, TENTAREI RECDNSTRUIR AS VERSÕES DA DRIGEM DA MENINA

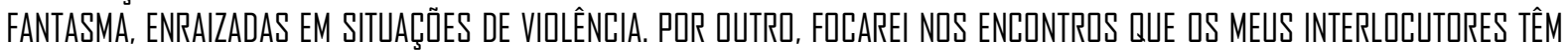
VIVENCIADO CDM ELA, NA DIFUSÃ DE SUA EXISTÊNCIA - QUUE FOI AMPLIFICADA DESDE QS RLMMRRES LOCAIS ATÉ CHEGAR A INSTÂNCIAS MEDIÁTICAS MAIORES - E NAS CONSEQUÊNCIAS QUE ELA TRDUXE. ISSO ME LEVARÁ A REFLETIR SOBRE US PRDCEESSDS DE PATRIMUNIALIZAÇ̃̃̃ E TURISTIFICAÇÃ̃ E SUBRE A IMPORTÂNCIA QUE AS "EXPERIÊNCIAS EXTRAORDINÁRIAS" PODEM TER PARA GERÁ-

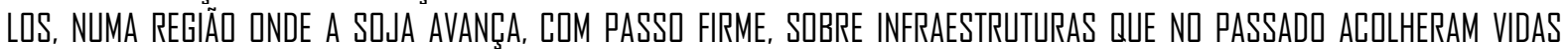
HUMANAS E QUE HIJE SE ENCDNTRAM, APARENTEMENTE, DESATIVADAS.

PALAVRAS-CHAVE: FANTASMAS, PATRIMÎNIL, TURISMU, DESPCVVAMENTD, LUGARES DE MEDU

\section{La entrada}

Casi siempre era Rema la que iba a ver si podían pasar al comedor de los cristales. Al segundo día vino al living grande y les dijo que esperaran. Pasó un largo rato hasta que un peón avisó que el tigre estaba en el jardín de los tréboles, entonces, Rema tomó a los chicos de la mano y entraron todos a comer.

(“Bestiario", Julio Cortázar) 
En abril de 2016, en una de mis estadías en el partido bonaerense de Balmaceda,1 donde llevo a cabo mi investigación doctoral en antropología, escuché por primera vez una historia que en mis posteriores visitas se volvería recurrente:

Mientras desayuno, Jorge, el encargado del hotel donde paro, me dice que, "como yo siempre ando por los pueblos", hay un lugar que me puede interesar. Se trata de una estancia de principios del siglo XX llamada "El Rocío", cuyo casco está totalmente abandonado y en la que supuestamente quedan aún los restos de un zoológico emplazado por sus antiguos dueños, que eran muy ricos. Jorge me cuenta, entonces, una historia conocida en Balmaceda. Un día, mientras les estaban dando de comer a los animales, la hijita del dueño de la estancia se acercó demasiado a la jaula del león, metió la cabeza entre los barrotes y el animal le arrancó la cabeza de una mordida. Hace unos años, por otro lado, una señora aficionada a la fotografía fue a sacar fotos en las ruinas y, cuando las miró en su casa, encontró la imagen de una niña espectral -el fantasma de la decapitada por el león- en una de las ventanas de la capilla de la estancia. Desde entonces, mucha gente se acerca a "El Rocío" atraída por la historia. En el hotel se hospedó, de hecho, una vez, un hombre que había viajado a Balmaceda exclusivamente para ir a la estancia de excursión fotográfica (nota de campo, abril de 2016)

En viajes posteriores, les pregunté acerca de esta historia a varios de mis interlocutores balmacedenses, quienes hicieron relatos similares, con alguna que otra diferencia sutil: a veces, la decapitada era la hija del dueño de la estancia, a veces su nieta; en algunos casos, agregaban detalles acerca del zoológico, como, por ejemplo, que tenía un oso polar y máquinas para hacer hielo a fines de mantenerlo aclimatado.

Pronto, pude saber que la estancia "El Rocío" había sido el emprendimiento productivo que, a fines del siglo XIX, le había dado origen a la región balmacedense de Severino Hernández. Eran las épocas del auge del modelo agroexportador y Severino Hernández, su creador, donó -procedimiento común en ese entonces- lotes de su campo para construir la estación de tren y emplazar las ferrovías que mantendrían conectada a la localidad y a la estancia con las zonas circundantes y la ciudad de Buenos Aires. En la década de 1920, la familia Mentaberry, segunda poseedora del establecimiento tras la quiebra de los Hernández, se ocupó de construir una escuela y una capilla neogótica para el pueblo, así como de ampliar el casco original de la estancia, proceso en el cual mandó a construir un zoológico y una enorme pajarera, que, según cuentan, albergaba miles de pájaros exóticos. Tras la quiebra de los Mentaberry, una tercera familia, los Esteche, oriundos de Mendoza, adquirieron la estancia y los campos y fundaron un enorme vivero, desactivado en la actualidad.

\footnotetext{
${ }^{1}$ Por cuestiones de confidencialidad (la importancia de mantenerla podrá apreciarse mejor con el correr del artículo), los nombres tanto de lugares como de personas aquí mencionados constituyen pseudónimos. Balmaceda es un municipio bonaerense cuyo territorio se encuentra dividido en diez "cuarteles" rurales, en uno de los cuales, Severino Hernández, transcurrieron los hechos y rumores que le dieron origen a este trabajo.
} 
Si bien la localidad de Severino Hernández llegó, hasta al menos la década de 1950, a tener más de mil habitantes, con el correr de la segunda mitad del siglo XX su población comenzó a menguar. Es que los procesos de tecnificación del campo argentino afectaron la cantidad de mano de obra necesaria para las tareas rurales y las familias que allí residían fueron abandonando la zona, en un proceso de "desertificación” (SILI, 2007) muy extendido en la Pampa húmeda. Para 2019, según los recuentos de población realizados en su pequeña delegación municipal, Severino Hernández contaba con alrededor de 50 o 60 habitantes.

Unos meses después de escuchar la historia del león y la niña -la real y la espectral, viajé al fatídico cuartel y pude recorrer las ruinas de la capilla neogótica y de su antigua escuela abandonada, que "hablaban" - por la calidad de sus materiales y por su bella factura arquitectónica- de la riqueza de los estancieros que los habían hecho construir. Los árboles y las plantas se extendían alrededor de las edificaciones conformando un frondoso bosque dominado por las acacias. Al fijar la vista en el horizonte, los troncos regulares, altos y verticales -en su pugna por llegar a la luz- se agrupaban con tal densidad que daban la impresión de formar paredes. Desde el interior del bosque, solo se escuchaban los cantos de los pájaros - a distintos timbres y volúmenes, formando capas sonoras- y el sonido lejano de alguna maquinaria o cortadora de pasto. La capilla neogótica, cuyo techo se había perdido tras un tornado en la década de 1970, se erguía entre los árboles, y restos de capiteles y columnas labrados yacían en torno suyo. Las ramas de los árboles, vistas desde su interior, formaban una suerte de cielorraso abovedado, y las enredaderas trepaban por las paredes desgastadas.

Esa tarde, además de mis acompañantes y yo, por el lugar pululaban otros visitantes, aprovechando el lunes feriado de sol; en las tres horas que pasamos recorriendo las ruinas, vimos a por lo menos tres grupos de personas que llegaban en auto y se aventuraban a las viejas construcciones.

La capilla y la escuela que la familia Esteche había hecho construir eran de fácil acceso - se encontraban a apenas unos doscientos metros de la estación de tren, también en ruinas y depredada-. Sin embargo, cuando quisimos incursionar "campo adentro" para llegar al casco de la estancia propiamente dicho - en que actualmente no reside nadie y donde aún se encuentran los restos del antiguo zoológico - no nos lo permitieron; al inicio del camino, desde un auto estacionado, una mujer interceptaba a los visitantes impidiéndoles que avanzaran, al grito tajante y acusatorio de: "esto es propiedad privada". 


\section{Introducción}

A lo largo de este artículo, me propongo reconstruir la historia de la difusión de las ruinas de Severino Hernández y de la existencia de su niña espectral, y su incidencia sobre la visibilidad de un espacio que, hasta hacía dos décadas, se encontraba oculto - para quienes no residían en "Severino"- en el interior de Balmaceda y en la oscuridad de un frondoso bosque. En este camino, intentaré darle visibilidad al peso que una entidad espiritual -es decir, un fantasma- comportó en el proceso de incipiente patrimonialización y turistificación -que, como veremos, no se oficializó completamente en parte por la controversia que despertó precisamente el fantasma infantil-. Al final del artículo, por otra parte, esbozaré una breve reflexión acerca del estatus de las entidades espirituales -como las que aquí me han convocado a la escritura- al interior de los artículos académicos.

Para elaborar este escrito, me he valido de mis notas de campo, producto de mis actividades de observación participante durante mi trabajo etnográfico en Severino Hernández y en otras pequeñas localidades de la zona, que vengo frecuentando desde 2016 hasta la actualidad. También, he recuperado información de entrevistas a algunos de los agentes de este proceso de visibilización de las ruinas, así como de materiales de la prensa impresa local.

El partido de Balmaceda se encuentra "en el corazón de la Pampa Húmeda”, al noroeste de la provincia de Buenos Aires. Sus actividades económicas giran en torno de la producción agropecuaria, la industria, el comercio y los servicios; en la actualidad, el $45 \%$ de su PBI proviene del agro, con un claro predominio de las actividades agrícolas por sobre las ganaderas y tamberas, incluso en aquellas zonas en las que históricamente habían predominado estas últimas. Para 2010, Balmaceda tenía 41.336 habitantes (INDEC, 2010) de los cuales apenas 8.114 residían fuera de la ciudad cabecera, es decir, en pequeñas localidades, tales como Severino Hernández, o bajo la forma de población rural dispersa.

Esta tendencia demográfica - consistente en el crecimiento de las localidades pequeñas e intermedias y al decrecimiento de las aglomeraciones rurales- ha sido señalada y explicada, para la región pampeana en general, por distintos autores (VAPNARSKY y GOROJOVSKY 1990; SILI, 1999 y 2007; ALBADALEJO 2006; RATIER, 2009 y 2018) a partir de los cambios que experimentó el sistema productivo argentino a lo largo del siglo XX. En la década del 1940, el modelo de sustitución de importaciones y el requerimiento de trabajadores para la industria generaron una primera oleada migratoria; este proceso se 
intensificó, luego, en los años 1960 con la tecnificación del sector agrícola y, aún más en los 1990, con la sojización y el desarrollo de la agroindustria (GRAS y HERNÁNDEZ, 2013; MUZLERA, 2013; CHAZARRETA y ROSATI, 2016), cada vez más extendida por el territorio argentino. La localidad de Severino Hernández, con sus propias inflexiones locales, ha formado parte, como lo hemos mencionado en el apartado precedente, de este proceso de desvitalización laboral y demográfica.

Sobre este trasfondo general, a fines de la década de 1990 y principios del 2000, la bibliografía constataba la emergencia, en pequeñas aglomeraciones de una pampa socialmente desertificada (SILI, 2007), de procesos "revalorización patrimonial” (RATIER, 2018, p. 53) plasmados en, por ejemplo, la creación de fiestas típicas, banderas, monumentos y museos. A lo largo del siglo XXI, estas acciones, en muchos casos emprendidas desde abajo, se fueron fortaleciendo y consolidando a través de programas específicamente orientados al desarrollo del turismo rural y, con él, de distintas acciones de patrimonialización. Estas propuestas y acciones han estado ligadas tanto a programas gubernamentales - de niveles nacional, municipal y, sobre todo, provincial- como no gubernamentales - por medio de, por ejemplo, ONGs-.2

En convergencia con estas iniciativas, podría decirse que, desde hace al menos una década, existe todo un género de turismo rural consistente en realizar escapadas cortas, generalmente los fines de semana, para practicar actividades como el ciclismo y, sobre todo, la fotografía. Los "pueblos despoblados" -como suelen ser denominados por sus visitantes-, los resabios ferroviarios y las ruinas de viejas edificaciones se han convertido en tópicos fotográficos recurrentes, cristalizados en decenas de sitios de Facebook e Instagram en los que viajeros -generalmente provenientes de la zona metropolitana de Buenos Aires y de ciudades intermedias bonaerenses- documentan sus avatares por los tortuosos caminos de tierra provinciales (FACCIO y NOEL, 2019). El lugar que aquí nos ocupa, es decir, la estancia de Severino Hernández y sus infraestructuras asociadas suelen aparecer en estos sitios de manera recurrente, junto al relato, por parte del fotógrafo o fotógrafa en cuestión, de la oscura historia de la zona y las proezas que implicaron llegar hasta allí.

2 Cecilia Pérez Winter viene realizando una investigación de largo aliento en torno a los programas gubernamentales ligados a la promoción del turismo en el interior de la provincia y a sus impactos, tomando como punto de partida los casos de los municipios de San Antonio de Areco y Exaltación de la Cruz (2013a, 2013b, 2014, 2016, 2017, 2019). 


\section{9:}

En la bibliografía específica, la turistificación del patrimonio bonaerense suele quedar asociada con la emergencia de activación patrimonial de ítems ya naturales, arquitectónicos o culturales como mecanismos más bien premeditados para generar valor y atractivos locales. En el caso que aquí abordamos, por el contrario, la alta visibilidad del complejo de ruinas agroexportadoras de Severino Hernández no surgió de manera planificada -ni por los dueños de la estancia y los campos, ni por los vecinos del pueblo, ni por el gobierno municipal de Balmaceda- sino que se vinculó con el arribo de visitantes de manera auto-convocada. Si bien, como se mencionó en el párrafo anterior, la llegada de visitantes sí forma parte de una tendencia turística de más amplio alcance, a nivel local - como veremos - no hubo ningún plan ni proyecto para que esto pasara.

En este marco, el punto que quisiera abordar y mostrar es el hecho de que la visibilización de la estancia de Severino Hernández y sus adyacencias ha emanado tanto de agentes humanos - llámeselos turistas, fotógrafos, historiadores, periodistas, agentes municipales y dueños de campos- como de un agente no humano, es decir, una niña espectral. En relación con esto, en la bibliografía acerca del turismo y el patrimonio en el interior rural bonaerense, la aparición de estos seres sutiles y de "experiencias extraordinarias" (Escolar 2010) asociadas a ellos no suelen estar visibilizadas, a pesar de que difícilmente cualquier persona que visite entornos rurales no pueda dejar de escuchar historias, para empezar, de luces malas y de espectros que cruzan rutas o que corren al costado de los caminos.

Este fantasma femenino, por otra parte, emergió en un espacio con rasgos muy específicos -en las ruinas de una capilla neogótica enclavada en un frondoso bosque-, que terminó de consolidarse, gracias a él, como "lugar de miedo" (LINDON, 2007). En los últimos años, han crecido los estudios que exploran este concepto a partir de casos específicos, vinculados, sobre todo, a entornos urbanos y en relación con la percepción de la inseguridad y del delito (LINDON, 2007; PYSZCZEK, 2012; GUZMÁN y ARIAS, 2017). En el medio rural, sin embargo, como veremos, también pueden emerger "lugares de miedo" - no relacionados, en este caso, con la comisión de delitos o, al menos, como veremos, no de delitos actuales -, pero sí capaces de engendrar una fascinación capaz de volverlos foco de visitas y, por lo tanto, de activar su valor turístico y patrimonial. 


\title{
Historias balmacedenses, 1996-1999
}

\begin{abstract}
Contando historias, mis narradores comenzaban a existir. La historia es todo. Es el amor y los crímenes, las formas de vida, las creencias y hasta las mentiras. (Pedro Golé, 68 años, periodista e historiador balmacedense).
\end{abstract}

A nivel local, los habitantes de Severino Hernández siempre convivieron con la estancia "El Rocío", sus devenires productivos y sus historias de fantasmas. La capilla neogótica y la enorme escuela hoy en ruinas habían sido los espacios educativo y religioso oficiales de la localidad hasta que, en la década de 1970, un fuerte tornado les produjo varios daños, entre ellos, la voladura de sus techos. Si bien en ese entonces las infraestructuras no habían quedado inutilizables, el hecho de que no se las refaccionara parece haber respondido, más bien, al desinterés de sus dueños y del Municipio. Es que, para esa década, a causa del decrecimiento poblacional, estas pequeñas aglomeraciones habían dejado de ser una prioridad para las instancias municipales balmacedenses, que menguaron la cantidad de recursos a invertir en ellas.

En la década de 1990, las historias en torno al zoológico de la familia Mentaberry y a la fantasma de la capilla -que, a nivel local, no solía estar asociada a la pequeña decapitada sino a otra niña con un destino igual de terrible, al que haré referencia oportunamente- se encontraban más o menos difundidas en el casco urbano de Severino Hernández, a pesar de que de allí no salían. Esta situación cambió en 1996, con la llegada a los pagos de Pedro Golé historiador y escritor balmacedense (actualmente de 68 años de edad).

Ese año, Pedro -que hasta entonces había trabajado como administrativo en una fábrica metalúrgica y eventualmente como periodista en distintos medios- y un amigo crearon un programa en la televisión local, Historias balmacedenses, en el que, cámara en mano, recorrían distintos rincones de su partido -desconocidos para una gran parte de los habitantes de la ciudad cabecera-. En uno de sus episodios, el equipo hizo una visita a "El Rocío”, donde entró en contacto por primera vez con las distintas y atractivas historias que contaban sus exiguos habitantes: la del emplazamiento de una pajarera con miles de aves exóticas traídas de todo el mundo y de un zoológico (con un león, una leona, un oso polar y una máquina para hacer hielo), la de la decapitación accidental de una niña por parte de la leona de los Mentaberry y la de la desaparición en la capilla de los restos de una niña cordobesa llamada Martita Stutz. 
En el episodio, se mostraban esos edificios y el casco de la estancia, en el que, a pesar de que ya no residía nadie, el mobiliario seguía intacto; allí estaban en pie todavía las bibliotecas llenas de libros, el piano de cola, la mesa de billar, el antiguo tocadiscos de pasta y la vajilla de lujo. Según Pedro, esta edición televisiva, en la que también se filmaron y exhibieron las antiguas pajareras e incluso la jaula de los leones, "causó furor" (entrevista personal, noviembre de 2017). En la nota, el periodista e historiador y distintos habitantes de Severino Hernández narraban la historia de las familias que habían poseído la estancia, marco en el que hacía aparición la trágica decapitación de una niña en garras de la leona; sin embargo, ningún fantasma había ingresado en la edición final.

Dos años después, en 1998, a raíz de la gran repercusión del programa televisivo, Pedro decidió crear una revista histórica porque "[la gente te dice] 'qué lindo programa', pero a los diez, quince días la gente ya se olvidó, o tiene memoria de lo que pasó pero no recuerda bien” (entrevista personal, noviembre de 2017). La nota de tapa del primer volumen, titulada "Dos historias, dos destinos" (1998) estuvo dedicada, a causa del impacto que había generado el informe televisivo, a "El Rocío” y versaba sobre las historias de ascenso y decadencia de las familias Mentaberry - propietaria de la estancia en las tres primeras décadas del siglo XX- y Esteche - que compró el establecimiento en la década de 1940 -. Esta periodización histórica se completó al año siguiente con un artículo del Padre Meinrado Hux -quien, hasta su muerte, investigó la historia de la provincia bonaerense- acerca del fundador de la estancia propiamente dicho, es decir, Severino Hernández. Los artículos buscaban dar cuenta de cómo era la vida cotidiana cuando el cuartel aún era un espacio vital y, sobre todo, responder a un interrogante normalmente asociado al tópico de las ruinas: ¿cómo explicar el pasaje de la opulencia a la decadencia más absoluta?

En ambos artículos, la clave era encontrada en el itinerario específico de las tres familias que habían tenido la estancia, a saber, los Hernández, los Mentaberry y los Esteche, narrada como una fábula moral (DAVIS, 1984) que consistía en un momento de riqueza, otro de dispendio y, finalmente, uno de decadencia -asociados más al carácter licencioso de las familias que a las condiciones estructurales de la economía argentina-. Había, sin embargo, un punto que seguía ausente en estas primeras "historias balmacedenses" escritas. En efecto, al igual que en la nota televisiva, Pedro, por pruritos históricos, había decidido no incorporar a la niña fantasma en la ecuación. Esta situación, no obstante, cambió en 2011, tras la difusión, por parte de un ama de casa y fotógrafa, de una experiencia personal escalofriante y de una foto "comprometedora". 


\section{Mirtha, 2011}

Mirtha nació y vivió toda su vida en Villa Quintana (Balmaceda, 1.826 habitantes), localidad surgida a principios del siglo XX en torno de un taller ferroviario del Ferrocarril Oeste, entonces en manos inglesas. En la década de 1990, con la Ley de Reforma del Estado menemista, Mirtha, junto con todos los quintanenses, vieron reducirse las fuentes de trabajo propias o de sus familiares y, con ello, la vitalidad de su localidad de residencia. En 2010, "Mir", que es ama de casa y esposa de uno de los pocos ferroviarios que se mantuvieron activos en taller, decidió comprarse una cámara de fotos y empezó a salir de excursión fotográfica buscando escenas para fotografiar, siempre, como me lo decía, “siguiendo al tren”. Mirtha, sin saberlo, formaba parte del hormigueo de viajeros que, cámara en mano, recorrían las vías activas e inactivas de la provincia de Buenos Aires.

Un domingo de 2011, su marido - que siempre oficia de conductor en sus viajes -, una prima y ella llegaron a la estación de Severino Hernández. En ese entonces, no tenían grandes expectativas sobre lo que allí encontrarían, puesto que, para ese entonces, en Villa Quintana no estaban muy difundidas las anécdotas acerca de las ostentosas construcciones del cuartel rural. Para Mirtha, se trataba simplemente de conocer y fotografiar una estación y un pueblo cercano más, como lo hacía todos los fines de semana.

En una charla que mantuvimos en 2018, me contó los acontecimientos que vivió en esa primera visita, sin que yo le preguntara siquiera por ellos; la narrativa que transcribo a continuación se abrió en el curso de una charla informal de manera, para mí, inesperada. Si bien yo ya conocía los rumores en torno de Severino Hernández, no sabía en ese entonces que estaba frente a la persona que había contribuido a amplificar la historia de su espectro infantil. A continuación, transcribo su narración, tal como la registré rápidamente en mis notas de campo:

Mirtha me cuenta que, con su marido, su prima (que vive en una localidad vecina) y su perrito, llegaron con el auto a la estación de tren de Severino Hernández, que estaba abandonada. En el andén, se sentaron a tomar unos mates y, al rato, ella decidió "cortarse sola" e ir a explorar el caminito que se abría desde la estación. En esa zona, el pueblo está lleno de monte y bosque -dado que a mediados del siglo XX en la estancia había un enorme vivero cuya vegetación, una vez desactivado, empezó a crecer descontroladamente-; Mir se adentró con su perrita, cámara en mano, entre los árboles y, tras una pequeña caminata, una capilla apareció, repentinamente, frente a sus ojos. Era un edificio antiguo, sin techo, en ruinas, 
invadido por la vegetación. No podía creer la belleza de esa construcción entre los árboles, se sintió fascinada: "me quedé muda", dice.

En el lugar no había nadie más; solo se escuchaba el canto de los pájaros y el sonido de sus pasos. Al ingresar en la capilla, sintió, rápidamente, algo que describió como "una presencia”, “una sombra”, “una presión” que, pegada a su espalda, iba siguiendo sus pasos. Su perrita también la acompañaba; caminaba entre sus piernas, temblando, totalmente asustada. Poco a poco, esta "sombra” se le había ido haciendo cada vez más fuerte, cada vez más palpable, hasta llegar a niveles insoportables. En un momento, escuchó, apavorada, que una persona silbaba, aunque no vio a nadie. Al rato, su prima apareció en la capilla; Mir le preguntó si era ella la que había estado silbando y la prima le respondió que no, que para nada. Mirtha sintió, entonces, tanto miedo que no pudo tolerar seguir ahí adentro ni un minuto más: salió corriendo del bosque, ${ }^{3}$ sin pararse a pensar siquiera en lo extraño, a los ojos de su prima, de su comportamiento. Cuando llegó al auto de su marido, le preguntó si era él el que le había silbado y le respondió, también, que no; le dijo que lo que sí había hecho hacía unos minutos había sido pegar unos gritos porque la perrita, que estaba con él, se había asustado y había salido corriendo en línea recta hacia el monte. Mir, entonces, le dijo: “¿pero cómo?, ¿estuvo con vos todo el tiempo la perra?", a lo que su marido respondió "sí, estuvo conmigo todo el tiempo, desde que estábamos en la estación y ustedes se fueron”; "pero si yo estuve con la perrita todo el tiempo que duró el paseo", respondió ella. Estas situaciones extrañas e incongruentes la dejaron muy perturbada. En nuestra conversación en su casa, Mir me remarca todo el tiempo que nunca le pasó nada así, que ni siquiera es religiosa, que nunca “creyó ni no creyó” en fantasmas, que nunca se preguntó por ni se ocupó de esos temas.

Esa noche, cuando con su marido volvieron a su casa en Villa Quintana, recibió una llamada de su prima, que también había sacado fotos y las acababa de bajar a la computadora. Le dijo: "Te voy a mandar algo; vos miralo". Mirtha empezó a ver las fotos y, en una de ellas, en la ventana de arco de medio punto de la capilla, se podía ver a una chica asomada, con la cabeza girada, en tres cuartos perfil, con unos cachetes muy regordetes. Se la mostró al marido. La imagen era muy clara. La subió, junto con otras de la capilla, a su Facebook (donde solía postear las fotos de sus excursiones fotográficas). Al día siguiente, "se armó un revuelo, ardió

\footnotetext{
${ }^{3}$ En su artículo "Violencia/miedo, espacialidades y ciudad", Lindón (2007) explica que, en entornos urbanos, "la espacialidad de la violencia/miedo puede derivar de las formas-objetos que materialmente integran un lugar. Por ejemplo, una construcción abandonada, viviendas degradadas, una zona ferroviaria en desuso" (p. 11); aquí, se da, precisamente, este tipo de perfil edilicio en el entorno de, además, a otro tipo de lugar de miedo, es decir, un bosque, entorno que, según la misma autora, "forma parte de las cuencas semánticas más reiteradas en la historia de la humanidad" (p.11)
} 
la red”. Los comentarios proliferaban y la llamaron del Canal 6 de Balmaceda, pidiéndole que explicara la historia de su foto. "Y yo se la conté igual que como te la conté a vos ahora", me dice.

Mirtha me dice que el marido de su hermana, "que es psicólogo y que por eso no cree en nada asî", trató de buscarle una explicación racional a la foto; le dijo que era "no sé qué de una ilusión producida por el vidrio, un juego de reflejos". Mir, sin embargo, objeta: "pero si la capilla no tenía vidrios en las ventanas”.

La cuestión es que la foto se hizo famosa y cada vez más la gente empezó a ir a "El Rocío”, interesada en sus edificios en ruinas y en su fantasma infantil.

Al poco tiempo, un día, en la casa de Mirtha se presentó un policía con una carta documento para ella. La había enviado uno de los hijos de una de las dueñas de la estancia. En el escrito, la intimaban por haber difundido la foto y la amenazaban con presentar una demanda, a causa de que el lugar donde ella había estado caminando y fotografiando era propiedad privada. Mirtha se asustó mucho. Borró la foto de su Facebook y se asesoró con un abogado amigo; cuando le contó la historia, él "se cagó de risa": le parecía imposible que le hicieran un "lío legal" por sacar una foto de un fantasma y de un lugar que, encima, no tenía señal o cartel de "privado" o "prohibido pasar". Le dijo que ella tampoco tenía la culpa de "todos los boludos que, después de la foto, fueron hasta ahí”.

Sobre la niña-fantasma, Mirtha me dice que no era la del zoológico o que, por lo menos, eso le contaron; recuerda haber escuchado que era de una chica que habían traído del Chaco o algo así, pero no sabe muy bien para qué. Me cuenta que dicen que, a la chica, la habían matado y enterrado en el terreno de al lado de la capilla. (Nota de campo, julio de 2018)

Mirtha, tal como me lo contó, retiró las fotos comprometedoras del fantasma de las redes rápidamente. A pesar de que luego de eso retornó a la localidad en varias ocasiones, no volvió a tener ningún encuentro con el espectro juvenil; en relación con esto, durante la charla, nos preguntamos por qué la niña no habría vuelto a aparecer: ¿sería que se había amedrentado por toda la gente que comenzó a llegar al lugar para visitarla?

Tomando parte en este proceso, en 2011, Pedro Golé decidió publicar un nuevo artículo sobre El Rocío, con el que se contribuiría a ampliar aún más la difusión de la historia de la estancia y, ahora también, la de Mirtha. 


\section{Historias balmacedenses, 2011}

La nota de tapa de la revista Historias balmacedenses de 2011 se titula: "La aparecida de El Rocío” y, ya desde su título y la estética de tapa, puede verse que sus evocaciones son claramente diferentes de las de las publicaciones de 1998 y 1999. En el ejemplar de 1998, cuya nota de tapa es: "El Rocío, una historia extraordinaria”, se nos muestra, en la esquina inferior izquierda, apenas una fotografía de la capilla neogótica rodeada de plantas. Mientras tanto, en la segunda, de título más sugestivo, se superpone una imagen de los arcos de la antigua construcción con la de una niña que, desde un mundo en blanco y negro, sonríe pavorosamente. La imagen sirve, en sí misma, de explicación al lector: esa niña alguna vez de carne y hueso es la dueña del alma que actualmente vaga en pena por los pagos de El Rocío. Si los artículos de los años 1990 respondían a la pregunta acerca de las ruinas y la decadencia de las familias que habían sido dueñas de la estancia, en "La aparición de El Rocío”, la inquietud de base para la escritura se vincula esencialmente con el fantasma: ¿quién es?, ¿por qué aparece, precisamente, en ese lugar?, ¿hay respuestas históricas para su presencia?

Aquí no se cuenta ya la historia de la pequeña decapitada por el león, sino otra más reciente y de raigambre local, pues era la más difundida en el propio cuartel de Mentaberry. El relato es, a grandes rasgos, como sigue. El mendocino Lucio Esteche compró la estancia El Rocío en la década de 1940 -los actuales dueños son, de hecho, sus descendientes-. Al poco tiempo, se radicó allí y estableció un vivero importante. En Mendoza, Lucio tenía un hermano abogado llamado Antonio, que, en 1938, fue incluido en la lista de sospechosos por la desaparición de una niña llamada Marta. Martita, como se la llamaba en las notas periodísticas de la época, había salido de su casa para comprar una revista y nunca más había vuelto. El caso había conmocionado, en su momento, a la opinión pública y a la prensa, y había desencadenado una investigación policial que nunca había llegado, sin embargo, a dar con el asesino. El cuerpo de Martita, en la actualidad, continúa desaparecido.

Si bien Antonio, el hermano del dueño de El Rocío, fue desvinculado del caso -nunca quedó claro si por su presunta inocencia o por su posición influyente en la sociedad mendocina de la época-, en Severino Hernández, se rumoreaba que él había sido el asesino. Según se contaba, su hermano, para protegerlo, había hecho trasladar el cadáver de la niña a su estancia bonaerense, donde lo habían incinerado en el horno de la panadería, ubicada a unos cien metros de la capilla; sus cenizas, posteriormente, habían sido esparcidas por la iglesia, razón por la cual el espectro se manifiesta precisamente en ese lugar. 
$\mathrm{El}$ artículo de la revista, que reconstruye esta historia a partir de varios testimonios de otros autores, se mueve, como en el caso de Mirtha - que nunca “creyó ni no creyó en estas cosas - entre el creer y el no creer. ${ }^{4}$ Por un lado, cita varios testimonios encontrados en un blog de internet dedicado a las fotos de El Rocío en el que ex residentes en la zona compartían sus testimonios y opiniones, tales como el siguiente:

Lucio y Antonio Esteche eran hermanos (...) A mí me impresionó mucho ese rapto y asesinato (el de Martita); yo tenía ocho años y era sobrina de uno de los dueños de la Farmacia Franco Inglesa, en ese entonces una de las más importantes del mundo.

Mis tíos eran amigos de los Esteche. Yo conocí la estancia de ellos y vi el horno para hacer ladrillos donde Esteche "el asesino" quemó a Marta. La esposa de Lucio Esteche estaba muy apesadumbrada ya que se trataba de su cuñado.

Delante de mí, contó todo a mi tía, su amiga. Se pueden imaginar que estas cosas no se olvidan. La estancia era muy linda y yo, una nena de ocho años, jamás olvidé lo que escuché. Hoy tengo 79 años y recuerdo todo como si fuera ayer. (CAPUTO, 2011, p.37)

Hacia el final del artículo, no obstante, el discurso de la "Historia” entra en tensión con el del "mito" y, con un argumento de índole histórica, el autor desmiente que el cuerpo de Martita hubiera sido desaparecido en El Rocío en tanto "la fecha de su desaparición (año 1938) no coincide con la llegada de los Esteche a El Rocío, ocurrida entre 1941-42" (CAPUTO, 2011, p. 39). La tentación de la "leyenda", sin embargo, vuelve a emerger y el autor escribe que "el fantasma no sería el de Martita Stutz" pero "sí podría ser el de la niña que (...) se acercó demasiado a la jaula de la leona y fue decapitada por esta” (CAPUTO, 2011, p.39). Esta idea, sin embargo, es rápidamente desechada y la nota cierra con una pequeña reflexión acerca de las leyendas urbanas. Las leyendas urbanas suelen ser muy poderosas, sobre todo cuando encierran un componente místico religioso y se presentan como hechos sociales sucedidos. Tienen su momento de euforia para luego languidecer y sobrevivir en un estado letárgico. Hasta que un hecho cualquiera, fortuito como en este caso, las recupera y las revive en los memoriosos que rápidamente sacuden sus arcones, evocan

\footnotetext{
${ }^{4}$ Sobre el "creer" como una suerte de estado de la persona, bajo ciertas circunstancias, más que como la actualización automática de un cuerpo de creencias, la observación ya aparece en un clásico, a saber, Brujería, magia y oráculo entre los Azande de Evans-Pritchard: "las creencias (...) no son estructuras ideacionales indivisibles sino que constituyen asociaciones laxas de nociones (...) en la vida real no funcionan como un todo, sino a fragmentos. Un individuo en una determinada situación toma lo que le conviene de las creencias y no presta atención a los demás elementos que podría utilizar en situaciones distintas. De ahí que un único acontecimiento pueda evocar cierto número de creencias distintas y contradictorias en distintas personas" (EVANS-PRITCHARD, 1976, p. 492). Para un abordaje más reciente sobre la cuestión, ver BENDER (2007), VIOTTI (2010) y SEVERI (2010).
} 
vivencias y remueven lejanas conversaciones escuchadas a medias, entre el susurro y la media voz de los mayores. Entonces la leyenda aletea entre la credulidad y la incredulidad con los elementos sobrenaturales o inverosímiles que la caracterizan. (CAPUTO, 2011, p. 39)

Ahora bien, por más reparos que, a la hora de la racionalización, haya entre el creer y el no creer, queda claro que, con la revitalización y la amplificación de las historias que se cuentan en torno a "El Rocío", el flujo de visitas -entre las que figura la mía propia, primero por curiosidad y luego por interés etnográfico- aumentó considerablemente, con picos en los fines de semana, aunque también con presencia de personas durante la semana. La capilla y la antigua escuela suelen recibir visitas provenientes de las cercanías, de la región metropolitana de Buenos Aires y, también, de turistas extranjeros. En mis estancias en Balmaceda, he conocido a decenas de personas que se han aventurado a Severino a pasear algún fin de semana; algunos de ellos van simplemente en un plan recreativo, aunque hay también quienes se acercan con interés fotográfico o, incluso en algunos casos, con aparatos específicos destinados a captar presencias sutiles. He conocido, en efecto, a personas que han acampado por la noche con la expectativa de encontrarse con la niña espectral. El espíritu ya de la pequeña decapitada, ya de la pequeña Martita- siempre es parte de los comentarios acerca de la visita: ¿'se sintió algo especial?, ¿no se sintió nada?, ¿tuvieron miedo?

Precisamente, la experiencia del miedo es parte de lo que se valora y procura al visitar Severino Hernández, que, entre quienes no residen en la aglomeración, se ha transformado en un espacio asociado a las historias "malditas". Así, el hecho de que este cuartel rural se haya difundido como un lugar de miedo - en virtud de sus ruinas, su bosque, su historia violenta y su pequeña habitante espectral- lo ha convertido en un espacio capaz de engendrar, sino una "topofilia" arraigada (TUAN, 2007), al menos sí un terror espacial fascinante.

Mientras tanto, parte de la familia Esteche - descendientes de Lucio y Antonio- ha empezado a intentar controlar la llegada de personas a sus dominios -aunque, como veremos, la propiedad de esos dominios es un tema que se ha puesto en discusión-.

\section{Mientras tanto, los Esteche, 2018}

El "aluvión" - como lo definió el historiador Pedro Golé - de visitantes a la estancia y a sus inmediaciones tomó desprevenidos a sus dueños - un extenso conjunto de hermanos y 
medio hermanos -, quienes, deslocalizados (SILI, 2007), como muchos dueños de campos de la provincia, residen fuera de Balmaceda, en su mayoría en la ciudad de Buenos Aires. En la actualidad, el casco de la estancia continúa desocupado -apenas están habilitadas otras dependencias como lugar de residencia - y las hectáreas que lo separan de la estación de tren, la capilla y la escuela - más accesibles desde el pequeño casco urbano - se encuentran arrendadas a una empresa local dedicada a la agroindustria y estrictamente vigiladas por cámaras de seguridad - en parte en reacción a los visitantes que solían incursionar campo adentro para encontrar el antiguo zoológico-.

Desde épocas tempranas, la familia se había mostrado reticente a la explotación turística de su patrimonio. En 2006, por ejemplo, rechazaron invitaciones tanto por parte del municipio como de la comisión de patrimonio municipal para efectuar algún tipo de formalización para fomentar el turismo en sus dominios. A esta reticencia con las autoridades municipales se ha sumado, por otra parte, la toma de acciones contra quienes contribuyeron a amplificar, con menor o mayor intención, la fama de su estancia. Muestra de ello son las cartas documento que recibieron Mirtha y el historiador Pedro Golé, a quien además han llamado más de una vez para pedirle que deje de hablar en los medios porque "estamos acobardados, es una locura de gente" (nota de campo, noviembre de 2017).

A raíz de esta situación, Golé investigó el estado catastral de la escuela y de la capilla en ruinas, y descubrió que la familia Mentaberry, quien las había construido a principios de siglo, las habría donado respectivamente al Consejo de Educación y a la Curia, con lo cual serían propiedad del público en general -no así el casco de la estancia propiamente dicho-. En los hechos, no obstante, la familia Esteche procede, hasta donde puede, como si los espacios fueran privados. ${ }^{5}$

A causa de esta explosión turística -experimentada como una invasión-, en los últimos años la familia comenzó a intentar ejercer un mayor control sobre sus dominios. Como lo mencionamos, los campos que rodean al casco de la estancia fueron arrendados para plantar soja y oleaginosas a una empresa local que se dedica a las actividades agroindustriales y afines y, en la zona de ingreso a las antiguas construcciones de la estancia -que continúan deshabitadas y llenas de muebles antiguos- se han colocado cámaras de seguridad. En mi

\footnotetext{
${ }^{5}$ Como lo observa Tim Edensor (2005), geógrafo que estudió establecimientos industriales en ruinas en Reino Unido, los lugares que se encuentran en estado de "abandono" suelen desafiar las categorías ordenadoras del espacio - al menos las occidentales-, entre las que podemos mencionar especialmente la distinción público/privado.
} 
último viaje de campo (en septiembre de 2019), se rumoreaba que los Esteche habían enviado una carta documento a un fotógrafo curioso que se había aventurado al casco de la estancia; las cámaras de seguridad lo habían captado y su identidad había quedado en evidencia porque, días después, había subido un álbum de fotos a la página de Facebook "Pueblos de Buenos Aires”, que tiene más de cien mil seguidores.

En cuanto a la capilla y a la escuela, ubicadas más cerca del casco urbano de la aglomeración, parte de la familia tomó la iniciativa de emprender allí una modesta "industria del patrimonio" (GORDILLO, 2018: 23). Los fines de semana, ambos edificios se abren oficialmente a las visitas a cambio de una suma de dinero. En este proceso, los propietarios desmontaron pequeñas sendas a modo de camino y colocaron discretas cintas de colores indicando los distintos recorridos posibles que se pueden hacer por el bosque. A través de la realización de reservas, el espacio se ofrece, además, para visitas guiadas a grupos y para locación para books fotográficos; para difundir y gestionar estas actividades, el año pasado, se abrió un sitio web donde, en el Home, se puede leer la siguiente descripción:

La estancia El Rocío (...) respeta la filosofía que ve a la tierra como un préstamo que nos hacen las generaciones futuras. Por eso es que, además de las actividades productivas comunes a los campos de la Pampa húmeda nos preocupamos por preservar el patrimonio histórico y de flora y fauna. Esto nos permite ofrecer una experiencia única de contacto con la naturaleza y con la historia de nuestra región.

Como en aquellas notas de la revista Historias balmacedenses de la década de 1990, en este relato oficial de los dueños no hay, empero, rastros del pequeño fantasma infantil que a veces asola la capilla y sus inmediaciones. En este punto, resulta sugestivo que, desde 2016, un domingo al mes, la familia Esteche haya comenzado a organizar misas en la capilla donde Mirtha y otros tantos más se sintieron acosados por la presencia de aquella niña muerta violentamente. ${ }^{6}$

Mientras tanto, Mirtha y demás fotógrafos con quienes he hablado se quejan: la capilla con menos "monte" - es decir, modificada por acciones tendientes a su conservación- "es menos

\footnotetext{
${ }^{6}$ Desde el Chaco salteño, Gastón Gordillo captura también la realización de misas sobre los escombros de una antigua ciudad española destruida por un terremoto en el siglo XVII y de la que en la actualidad se dice que es sísmica en sí misma y peligrosa para la región. El autor interpreta este gesto por parte de la iglesia y las autoridades oficiales como "un exorcismo de la maldición en su lugar de origen" (GORDILLO, 2018: 131).
} 
interesante”, y las quejas ante el control se hacen oír, o leer en los anuncios en tranqueras que indican “propiedad privada”, vandalizados y traspasados a los saltos una y otra vez.

\section{"Vos vas a salvar al Teatro": patrimonio y "experiencias extraordinarias"}

A lo largo de este escrito, he intentado seguir historias que se cuentan en torno de El Rocío, incorporando a los principales actores intervinientes. En este caso en particular, un punto que, desde el comienzo, se me había revelado sugestivo era el hecho de que una de las figuras que había contribuido a la creciente publicidad de la zona había sido un no humano, es decir, un fantasma. Si bien la arquitectura ya era, desde antes de 2011, un foco de interés para quienes se acercaban a la localidad, la aparición del espectro femenino contribuyó, sin dudas, a su mayor popularidad. Fue luego de su aparición, por ejemplo, que los Esteche empezaron a intentar ejercer el control de sus dominios arquitectónicos, a los que hasta entonces se habían mantenido más bien indiferentes.

Ahora bien, ¿cuán excepcional es este caso, con su arquitectura singular y su historia de fantasmas? Como lo mencionaba al comienzo, en la bibliografía acerca de procesos patrimonializadores y turistificadores en la región rural bonaerense no suelen cubrirse fenómenos del tipo que aquí he tratado. Sin embargo, incluso más allá de este caso, en mi trabajo etnográfico en Balmaceda, he conocido a no pocos agentes patrimonializadores que han pasado por distintas "experiencias extraordinarias" (ESCOLAR, 2010), ya durante la realización de su trabajo, ya como motivación para emprender alguna gesta patrimonializadora. A modo ilustrativo, aquí quisiera presentar dos ejemplos más para visibilizar el tema. El primero de ellos es el de Américo, un escribano que evitó que, en la ciudad de Balmaceda, un teatro en ruinas - construido en épocas del modelo agroexportadorfuera demolido; su motivación inicial - casi el relato de una iluminación- fue una misteriosa voz incorpórea que le hablaba, como lo relata la siguiente nota de campo:

Américo, un hombre de 80 años pero que parece mucho más joven, me cuenta que él fue el responsable de que el Teatro de Balmaceda se haya recuperado. En los años ' 70 iban a demoler el teatro; hacía mucho se había incendiado y había riesgo de derrumbe. Los vecinos se quejaban porque "era un peligro". Américo me cuenta que, en esa época, en su escritorio de la escribanía, escuchó tres veces "una voz acá" (cuando me lo dice, se señala el costado debajo del oído) que le decía “vos vas a salvar el Teatro". Esa voz la escuchó tres veces. Entonces, pidió una reunión con el intendente de Balmaceda, que era un militar y habló con él. El hombre también quería recuperar el teatro, pero no estaba tan seguro. Jorge le dijo que, si no lo hacía, iba a organizar una manifestación; el militar se asustó ante esa amenaza de desorden público y lo escuchó. Finalmente, después de muchas negociaciones (que implicaron complicaciones con los dueños 
del teatro - que era privado-, con la gente de la demolición, con la provincia y con el municipio) logró salvar la sala, que es la que se conserva hasta el día de hoy (nota de campo, octubre de 2018).

Otro caso que aquí quisiera traer es el de Ana (52 años), museóloga a cargo del Archivo Municipal de Balmaceda y curadora de varios de los museos del partido; las experiencias de Ana con los objetos han trascendido, más de una vez, su tiempo y espacio:

Estamos tomando mate en el Archivo de Balmaceda, y le digo a Ana que su tío, curandero con el que he conversado muchas veces, me contó una vez que ella tenía videncia, pero que no se había atrevido a desarrollarla. Ella me cuenta que sí y que, muchas veces, esa videncia se activa con los objetos con los que trabaja. Hay dos historias particularmente vívidas. En una ocasión, una persona le trajo un pequeño revólver, pintado de naranja, que había pertenecido a un concejal de Balmaceda en la década de 1930. Ese hombre había matado a un contrincante político. Ana recibió el arma, la tomó entre las manos y tuvo una experiencia fuera de lo común. De repente, perdió la noción del lugar donde estaba y sus ojos vieron una especie de túnel negro que se angostaba; al final de ese túnel, vio, como si ella estuviera en el cuerpo del asesino, el arma en su mano, disparándose y a un hombre caer muerto. Después de tener esta visión, Ana quedó un rato largo como en trance. Las personas que estaban con ella la sacudían y no reaccionaba. Finalmente logró volver en sí pero le costó mucho trabajo. Se quedó muy asustada.

La segunda vez que le pasó fue cuando estaba armando y curando el Museo de Las Frutillas (otro cuartel rural de Balmaceda). La gente del pueblo había donado sus objetos para crear el acervo. En una ocasión, a Ana le trajeron una máquina de coser antigua. Cuando la tomó en las manos, vio, otra vez, el túnel negro, entró en trance y tuvo una visión: vio las manos de una viejita usando la máquina, vio la habitación en la que estaba; tuvo, además, una sensación de muchísima angustia - y sabe que esa angustia no era suya-. Otra vez, le costó mucho volver. Después, quedó agotada. Ana me dice que no quiere seguir desarrollando esta percepción porque tiene mucho miedo de no poder volver de esos trances (nota de campo, septiembre de 2019).

A riesgo de ser digresiva, no quería dejar de citar aquí situaciones como las que me han relatado Américo o Ana. No quisiera dar a entender aquí que las voces incorpóreas, los "viajes en el tiempo" o los fantasmas se configuran como entidades o eventos de la misma naturaleza. Sin embargo, lo que sí se podría decir es que todas ellas comparten el hecho de constituir, para las personas que las experimentan, "experiencias extraordinarias" (ESCOLAR, 2010), es decir, situaciones que irrumpen e interrumpen la textura de la vida cotidiana y su verosimilitud. Y, aun así, aunque extraordinarias, ellas no parecen ser, empero, excepcionales, a juzgar por el modo en el que han proliferado, al menos en mi experiencia de campo. Por ello, quisiera sugerir que para empezar a pensar cualquier acción sobre el espacio -tales como las patrimoniales que aquí he presentado- es, por lo menos, "etnográficamente honesto" (ESCOLAR, 2010, p. 307) reconocer, cuando aparecen, las "experiencias extraordinarias" -que tienen el poder, en muchos casos, de modificar el curso de las cosas-, así como también a los seres no humanos involucrados en ellas. 


\section{Reflexión final: "los espíritus son el problema"}

Cuando en mi campo emergió la historia de la pequeña niña fantasma, mi interés se despertó al mismo tiempo que mi desconcierto: ¿cómo incorporar analíticamente esta presencia espectral en el artículo? Para finalizar, por ello, quisiera tratar de pensar y explicitar el modo en el que, a lo largo de este artículo, la incorporé y dar cuenta, someramente, de otros caminos a partir de los cuales se podría profundizar en la temática.

El antropólogo escocés Jack Hunter (2018) y el argentino Diego Escolar (2010) se han tomado en serio y han reflexionado sobre "experiencias límite" para la razón académica que han aparecido en sus prácticas etnográficas - el primero, con un centro espiritista en Escocia y, el segundo, en la región de Cuyo con grupos huarpe -. En el recorrido conceptual que ambos autores hacen sobre el tratamiento que la Antropología ha dado a eventos y seres extraordinarios marcan, al menos, dos modalidades coincidentes. La primera, denominada por Hunter como enfoque relativista, sería aquella que incorpora los seres espirituales al análisis en virtud de que ellos son relevantes desde un punto de vista emic; dentro de esta postura, la tendencia es, no obstante, a concebir a dichos seres y situaciones como manifestaciones simbólicas de condiciones sociales específicas, es decir, a traducirlos sociológicamente. La segunda modalidad, a la que tanto Hunter como Escolar adscriben, consiste en no intentar reducir a fantasmas, espíritus o luces malas a razones sociales sino a considerarlos en toda su plenitud, aun cuando, en un principio, no parezcan tener significado. En este registro, Escolar (2010) propone experimentar y tratar de hacer una "antropología de las experiencias extraordinarias" (ESCOLAR, 2010) en sí mismas, sin buscarles un correlato racional; Hunter (2018), en una línea similar, se aventura por el mismo camino y va, incluso, más allá al instar a la realización de trabajos en conjunto con profesionales de disciplinas tales como la parapsicología.

Considerando estas dos posturas, puedo decir que, a lo largo de este texto, he evitado ensayar interpretaciones simbólicas tanto de los rumores en torno a la familia Mentaberry como de la aparición del pequeño espectro femenino. Esto no implica, empero, - desde mi punto de vista y a diferencia de los dos autores citados - que este tipo de análisis no pueda ser, con sus debidos reparos históricos y metodológicos, productivo. En cuanto a la anécdota de la leona, por ejemplo, fácilmente se podría hacer una lectura en términos de clase. No resultaría extraño que, en una situación de desigualdad social, apareciera un relato acerca de la muerte de la hija de un subordinado - el cuidador del zoológico - en manos de las bestias que exhibían 
y materializaban la opulencia de los patrones, a saber, los Mentaberry. Y, acercándonos al presente, también podrían ser relevantes los desplazamientos existentes con respecto a esa versión previa de la historia. Por ejemplo, para mis actuales interlocutores, la niña asesinada habría sido la hija o la nieta del propio dueño de la estancia en lugar de la de un subordinado; en su relato, la ostentación y los dispendios de la familia Mentaberry - objetivados bajo la forma de zoológico - se vuelven, como una enfermedad autoinmune, contra ellos mismos, amenazando su propia continuidad, en tanto es una persona de la generación más joven de la familia la que muere al final - en consonancia, por otra parte, con la decadencia de la estancia.

En relación con el fantasma que se le presentó a Mirtha, no me aventuré, en este caso, a realizar una interpretación en clave simbólica. En el libro de Janet Carsten Ghosts of memory (2007), la autora muestra cómo los fantasmas de familiares asolan a los residentes de una colonia ferroviaria india en decadencia; la autora elabora, así, una interpretación de la presencia de estos seres sutiles a partir de la categoría de memoria y en clave simbólica. En los casos que he recogido en Balmaceda - del que el de Mirtha forma parte -, sin embargo, es difícil encontrar una filiación personal del tipo de las que Carstel encuentra en su trabajo. En efecto, Mirtha no tenía conocimientos previos acerca de Severino Hernández ni vínculos familiares en la zona: ¿qué significado podría haber tenido la existencia de este encuentro?, ¿reflejo de qué situación social podría ser? Tal vez, en futuras aproximaciones, sería posible encontrar resonancias de este tipo, ampliando el número de casos e indagando en la historia de Mirtha. Mientras tanto, también cabe la posibilidad de que ese encuentro simplemente haya ocurrido, es decir, que simplemente se haya dado más allá del significado.

En todo caso, lo que he intentado hacer en este artículo no ha sido preguntarme el porqué de la aparición de esta niña fantasma - lo cual podría, no obstante, llevar a respuestas interesantes- sino en el hecho mismo de su aparición y en sus consecuencias, tanto en cuanto a las interpretaciones por parte de mis interlocutores como a sus efectos tangibles sobre el espacio practicado - que son siempre, en última instancia, sociales -. Podría decirse que aquí, con el objetivo de este artículo, que es mostrar la injerencia que un "no humano" puede tener sobre acciones patrimoniales, la pequeña niña fantasma ha sido incorporada al análisis en calidad de actante (LATOUR, 2008), es decir, como una entidad que, aun sin ser humana, "hace hacer". Los desencadenantes de su presencia, como hemos visto, no son menores: la llegada de viajeros, la proliferación de fotografías y relatos, la amplificación de rumores en los medios, el intento de turistificación de un sitio, la indagación en planos y catastros, las amenazas legales. 
Pensando en trabajos futuros acerca del tema, queda ahondar en los formatos que adquieren las experiencias extraordinarias que aquí he tratado - tan frecuentes en el "interior" bonaerense - atendiendo a sus rasgos materiales y simbólicos, y a las reacciones que ellas producen entre quienes las transitan, con mucha consciencia de un límite: el de no ahogar a cierta "sinrazón" que permanece en el flujo de la vida, ya invisibilizándola, ya domesticándola a través de las interpretaciones académicas.

\section{REFERENCIAS BIBLIOGRÁFICAS}

ALBADALEJO, Christophe. De la Pampa agraria a la Pampa rural: la deconstrucción de las 'localidades' y la invención del “desarrollo rural local”, Párrafos Geográficos, Año.5, No 1, 2006, p.27.53.

BENDER, Courtney J. "Touching the Trascendent: Rethinking Religious Experience in the Sociological Study of Religion”. En: Ammerman, Nancy T. Everyday Religion. Observing Modern Religious Lives. Oxford: Oxford University Press, 2007.

CAPUTO, Juan Luján. Dos historias, dos destinos, Historias para ser contadas. Año 1, Vol.1.

CAPUTO, Juan Luján. El caso de Martita Stutz y la aparecida de Montelén, Historias para ser contadas. Año 14, Vol. 67.

CARSTEN, Janet. "Introduction”. En Carsten, Janet (comp.): Ghosts of memory. Malden: Blackwell Publishing, 2007.

CHAZARRETA, Adriana y ROSATI, Germán. "Los cambios en la estructura social agraria argentina", en Kessler, Gabriel (comp.): La sociedad argentina hoy. Buenos Aires, Siglo XXI Editores, 2016, p. 86-107.

DAVIS, Natalie. El regreso de Martin Guerre. Barcelona: Bosch Ed, 1984.

EDENSOR, Tim. Waste matter - The debris of industrial ruins and the disordering of the material world, Journal of material culture, Vol. 10, N.3, 2005, p.311-322.

ESCOLAR, Diego. "Calingasta $x$-file": reflexiones para una antropología de lo extraordinario, Intersecciones en Antropología, $\mathrm{N}^{\circ} 11$, 2010, p. 295-308.

EVANS-PRITCHARD. Brujería, magia y oráculo entre los Azande. Barcelona: Anagrama, 1976.

FACCIO, Yanina y NOEL, Gabriel. Nostalgia is a weapon: utopías metropolitanas y ruralidad hiperreal, Quid 16. Revista de estudios urbanos, $\mathrm{N}^{\circ} 11$, 2019, p.109-136.

GORDILLO, Gastón. Los escombros del progreso. Buenos Aires: Siglo XXI, 2018

GRAS, Carla y HERNÁNDEZ, Valeria. El agro como negocio. Producción, sociedad y territorios en la globalización. Buenos Aires, Biblos, 2013. 
HUNTER, Jack. "Los espíritus son el problema”. 2018. Acceso en https://realidadtrascendental.wordpress.com/2016/02/14/los-espiritus-son-el-problemaantropologia-y-la-conceptualizacion-de-seres-espirituales/ (17/11/2019).

HUX, Meinrado. Máximo Fernández (1851-1916). El hombre que inició Montelén, Historias para ser contadas. Año 1, Vol.5.

LATOUR, Bruno. Reensamblar lo social. Una introducción a la teoría del actor-red. Buenos Aires, Manantial, 2008.

LINDON, Alicia. Violencia/miedo, espacialidades y ciudad, Casa del tiempo, vol.1, nº 4, 2007, p. 8 -14.

MAPE GUZMÁN, Fernando y AVENDAÑO ARIAS, Johan. Topofobias e imaginarios del miedo sobre el espacio urbano de la localidad de Fontibón, Bogotá, Colombia. Perspectiva geográfica, vol.22, $\mathrm{n}^{\circ} 1,2017$, p.49-68.

MUZLERA, José. La modernidad tardía en el agro pampeano. Sujetos agrarios y estructura productiva. Bernal, Universidad Nacional de Quilmes, 2013.

PÉREZ WINTER, Cecilia. Patrimonio y turismo rural en Argentina: Exaltación de la Cruz, un caso del campo bonaerense, Investigaciones turísticas, $n^{\circ} 6,2013(\mathrm{a})$, p.47-70.

PÉREZ WINTER, Cecilia. Patrimonialización, turistificación y autenticidad en Exaltación de la Cruz, Argentina, Estudios y perspectivas en turismo, Vol.22, 2013(b), p.785-804.

PÉREZ WINTER, Cecilia. La provincia de Buenos Aires (Argentina): de un espacio a un territorio turístico, Turismo - visão e ação, Vol.16, 2014, p.544-572.

PÉREZ WINTER, Cecilia. ¿'Tierra de gauchos' o 'Gaucholandia'? Autenticidad en San Antonio de Areco (Argentina), Pasos. Revista de turismo y patrimonio cultural, Vol. 14, n 5, 2016, p.1281-1296.

PÉREZ WINTER, Cecilia. Los procesos de patrimonialización y turistificación en la legitimación de paisajes desiguales, Sociedade e natureza, Vol.2, 2017, p.195-208.

PÉREZ WINTER, Cecilia. La diversificación y promoción turística en tiempos de 'nuevas ruralidades': de la costa atlántica al campo pampeano, Revista de ocio y turismo, Vol.13, n² 2019 (a), p. 68-85.

PÉREZ WINTER, Cecilia. La fotografía en los procesos de activación, resignificación y gestión patrimonial: los casos de Exaltación de la Cruz y San Andrés de Giles, municipios de la provincia de Buenos Aires, Argentina, Sophia Austral, n²2, 2019(b), p.129-151.

PÉREZ WINTER, Cecilia. El “retorno al campo” desde la mirada local. Redescubriendo los atractivos patrimoniales pampeano-bonaerenses (Argentina), Pasos, Vol.1, n²4, 2019(c), p.779-793.

PYSZCZEK, Oscar Luis. Los espacios subjetivos del miedo: construcción de la estigmatización espacial en relación con la inseguridad delictiva urbana, Cuadernos de geografía. Revista colombiana de geografía, vol.21, $\mathrm{n}^{\circ} 1,2012, \mathrm{p} .41-54$.

RATIER, Hugo. Poblados bonaerenses. Vida y milagros. Buenos Aires, La Colmena, 2009.

RATIER, Hugo. "Los pueblos rurales. Formas de vida, identidad y revalorización patrimonial”, en Ratier et. al: Antropología rural argentina. Etnografías y ensayos. Tomo II. Buenos Aires: Editorial de la Facultad de Filosofía y Letras, 2018. 
SEVERI, Carlo. Capítulo 3 "Memoria, proyección, creencia o la metamorfosis del enunciador". En: $E l$ sendero y la voz. Una antropología de la memoria. Grupo Ed. Sb. $1^{\text {a }}$ Ed. Buenos Aires. 2010, p. 219-172.

SILI, Marcelo. La fragmentation socio-territoriale. Une nouvelle logique de fonctionnement pour le monde rural. Le cas de la Pampa Argentine, L’Espace Géographique, Vol.28, n4, 1999, p. 289-299.

SILI, Marcelo. "Les espaces vides de la modernisation rurale. Dépeuplement et marginalisation des espaces ruraux en Argentine", en Van Celst, F. (comp.): Habiter et vivre dans les campagnes de faible densité. Clermont Ferrand: Ceramac, 2007.

TUAN, Yi Fu. Topofilia: un estudio sobre percepciones, actitudes y valores medioambientales. España: Melusina, 2007.

VIOTTI, Nicolás. El lugar de la creencia y la transformación religiosa en las clases medias de Buenos Aires, Apuntes de investigación del Cecyp, nº 18, 2010. 